\title{
Gastrointestinal Stromal
} Tumors with Unusual Localization: Report of Three Cases with a Brief Literature Review

\author{
Ahmet Fikret Yucel ${ }^{\mathrm{a}}$ Haldun Sunar ${ }^{\mathrm{b}}$ Adnan Hut $^{\mathrm{b}}$ \\ Ahmet Kocakusak $^{\mathrm{b}} \quad$ Ahmet Pergel $^{\mathrm{a}}$ Gul Barut $^{\mathrm{c}}$ \\ Suleyman Dikici ${ }^{\mathrm{d}}$
}

${ }^{a}$ Department of Surgery, Rize University Medical School, Rize; ${ }^{b}$ First Department of Surgery and 'Department of Pathology, Haseki Training and Research Hospital, and 'Department of Radiology, Istanbul University, Cerrahpasa Medical School, Istanbul, Turkey

\section{Key Words}

Gastrointestinal stromal tumors - c-kit · Surgical resection

\begin{abstract}
The most common tumors derived from the mesenchyme of the gastrointestinal system are stromal tumors. These tumors are typically seen in the stomach and small intestine and less frequently in the colon, rectum and esophagus and are very rarely located outside the gastrointestinal system. Cure is provided with complete surgical resection with resection borders free of tumor. Tumor size, mitotic index, localization, CD117 and CD34 negativity in immunohistochemical studies, mucosal ulceration and presence of necrosis help to predict recurrence of the illness and patient survival. In high-risk gastrointestinal stromal tumors (GISTs) there is an increased rate of recurrence and shortened survival despite complete surgical resection. Thus patients with a high-risk GIST should be given adjuvant therapy with imatinib mesylate. Sunitinib maleate is another FDA-approved agent only for cases who cannot tolerate imatinib or who are resistant to it. Herein we present three cases with GISTs in different locations of the gastrointestinal system with a review of the relevant literature.
\end{abstract}




\begin{tabular}{r|l|l|l}
$\begin{array}{r}\text { Case Reports } h \\
\text { Gastruenterolagy }\end{array}$ & $\begin{array}{l}\text { Case Rep Gastroenterol 2010;4:250-260 } \\
\text { Dol: } 10.1159 / 000319167\end{array}$ & Published online: July 26, 2010 & $\begin{array}{l}\text { O 2010 S. Karger AG, Basel } \\
\text { ISSN 1662-0631 } \\
\text { www.karger.com/crg }\end{array}$ \\
& & & \\
\hline
\end{tabular}

\section{Introduction}

Gastrointestinal stromal tumors (GISTs), a different histopathological group of intestinal tumors derived from mesenchyme, are seen rarely. Most of them used to be classified wrongly as leiomyoma, leiomyosarcoma or leiomyoblastoma on the false belief that their origin was smooth muscle [1-3]. Following the improvements in electron microscopy and immunohistochemical methods, it was shown that they originated from the intestinal pacemaker cells (Cajal cells). These cells, having both muscle and nerve cell properties, are located in the submucosa, muscularis mucosa and myenteric plexus in the gastrointestinal system $[4,5]$. Recently, more information was gained about the cell characteristics of these tumors by recognition and discovery of the CD117 antigen, c-kit protooncogene production, platelet-derived growth factor a (PDGFRA) and CD34 [6-8].

Although GISTs can be seen in any part of the gastrointestinal system, it has been reported that more than $50 \%$ of cases are located in the stomach $[2,3,7-9]$. The commonest symptoms of gastric GISTs are hemorrhage and pain [7, 10]. Most colon GISTs are asymptomatic and detected incidentally [11]. It is difficult to predict their metastatic potential because malignity does not have any obvious clinical and pathological findings [8]. A scheme was published how to predict the clinical behavior of GISTs, based on tumor size and number of mitoses in the consensus report of the U.S. National Institutes of Health in 2001 [5].

\section{Case Reports}

Case 1 was a 28 -year-old male patient with complaint of abdominal pain. An abdominal mass was detected during physical examination. Upper gastrointestinal system endoscopy and biochemical studies did not reveal any abnormalities. Computed tomography (CT) and magnetic resonance imaging (MRI) were carried out (fig. 1, fig. 2). Pathological examination of fine needle aspiration biopsy was consistent with a malignant mesenchymal tumor. Whipple operation was performed as there was pancreatic invasion. The patient was discharged on the 12th postoperative day without any complications.

Case 2 was a 62-year-old male patient with complaint of abdominal pain. Upper gastrointestinal system endoscopy revealed external pressure on the fundus of the stomach. A soft tissue mass protruding to the fundus of the stomach was found in MRI (fig. 3 ). Proximal gastrectomy was performed and the patient was discharged on the 9th postoperative day without any complications.

Case 3 was a 38-year-old male patient with rectal bleeding, abdominal pain and anemia. Endoscopy revealed no pathology in the upper and lower gastrointestinal system. Tc-99 scintigraphy revealed active bleeding in the upper left quadrant (fig. 4). A polypoid lesion was detected in capsule endoscopy in the proximal jejunum (fig. 5). Double balloon enterescopy showed a bleeding polypoid mass with a diameter of $2 \mathrm{~cm}$ which was located at the proximal $50 \mathrm{~cm}$ of the jejunal lumen (ig. 6 ). Segmental jejunal resection was carried out and he was discharged on the 6th day after the operation.

The general properties of the patients are summarized in table 1. Pathologic and immunohistochemical properties are summarized in table 2. C-kit was strongly positive in all patients (fig. 7).

\section{Discussion}

GISTs are rare submucosal lesions but are presently detected in increasing frequency following the increased use of upper gastrointestinal system endoscopy [7]. The most common gastrointestinal system location of GISTs is the stomach (52-60\%) [12]. Most GIST patients are detected in their 6th or 7 th decades, while only $10 \%$ are below 40 years of age [8]. In some studies, secondary malignancies (pre-diagnosis, con-diagnosis, 
post-diagnosis) are reported to be as high as $20-30 \%[9,13]$, and in one study it was only $5 \%[2]$.

Most patients are diagnosed incidentally as they have nonspecific symptoms or are asymptomatic [7]. In one study, it is stated that asymptomatic GISTs can be detected more frequently during routine endoscopic examination of the stomach, colon and rectum [9]. In another, as examination and endoscopic viewing of the small intestine is rather difficult, surgical operations done for irrelevant causes revealed GISTs mostly in the small intestine [13]. Incidental GISTs are claimed to have a low or very low risk of malignancy [9]. In our third case, the patient had a low-risk small intestine GIST. It was diagnosed by Tc-99 scintigraphy, capsule endoscopy and double balloon enteroscopy to determine the focus of bleeding preoperatively. This minimized the probability of unnecessary surgical interventions.

Abdominal pain (though not a rule) is the most common symptom [7]. In a study, all colonic GIST cases were symptomatic versus only $50 \%$ of rectal GIST cases [11]. In our cases, the most common symptom was abdominal pain. In the relevant literature, anemia and gastrointestinal bleeding are seen in $48 \%$ of cases in ulcerated lesions [7]. As the GISTs located in the stomach and duodenum were not ulcerated, there was neither bleeding nor anemia in our cases.

In some CT screening studies, big GISTs were found to have a tendency to grow lobulated and ectophytic, whereas the small ones had a tendency to grow into the lumen. In many studies, a radiological (CT) tumor size $>5 \mathrm{~cm}$ is found to be correlated with a malignancy potential $[14,15]$. The malignancy potential can be predicted by anatomical location, tumor size and mitosis rate [15]. Especially small intestinal GISTs have more malignancy potential than colonic and gastric ones $[15,16]$.

Endoscopic ultrasonography (EUS) is an important diagnostic tool [17]. Although endoscopic biopsies are not very useful in diagnosis, needle biopsies performed with EUS can be used to identify the cell structure and to study specific markers [3]. Additionally, some properties in EUS (tumor size, irregular borders) suggest malignancy [18]. In our cases we did not have a chance to use EUS.

Although in several studies especially the high-risk categories (high, medium, low, very low) are reported to be in similar percentages in all three anatomical locations [2,9], in a population-based study, $25 \%$ of patients were in the high-risk group [19]. The effect of the anatomical location on prognosis is debatable. In one study, anatomical location was found to be a prognostic factor independent from age, mitotic index and tumor size [16]. In another, the anatomic placement of the GIST was found to have an effect on the expression of CD34 and smooth muscle actin [20]. Recently a mutation in exon 9 of c-kit was found in small intestinal GISTs and this was related to an increase in tumor aggressivity [21]. However, in most studies it is reported that tumor size and mitotic index were the most important prognostic factors, that recurrence and death were more common in the patients in the high-risk group, and that these patients needed additional treatment $[5,8,11]$.

C-kit tyrosine kinase (CD117) positivity has recently been demonstrated to be at a level of $91-99 \%$ in GISTs, which paved way to the discovery of their cell origin and better diagnostic markers $[1,8]$. Although c-kit positivity is thought to be a criterion as a diagnostic factor for GIST (fig. 7), convincing reports also exist for kit-negative GISTs. These tumors are stated to have a similar tyrosine kinase receptor PDGFRA fraction mutation as kit $[1,11]$. While CD117 and CD34 are positive in recurrent and metastatic 
tumors, S-100 and desmin are found to be negative [7]. Other important histological properties are necrosis and ulceration $[3,11]$. Especially coagulation necrosis is thought to be related to malignant behavior [8]. In some studies, the existence of ulceration was found to be a statistically significant risk factor for recurrence [7, 8]. In all our cases c-kit and CD34 were found to be intensely positive. In the case with small intestine location, specific mitochondrial antibody was $100 \%$ positive. To determine the risk categories of patients, the criteria (table 3) specified by the US National Institutes of Health in 2001 consensus report were used [5]. Pathologic and immunohistochemical properties of the cases were evaluated by means of these criteria (table 2).

Surgical resection is the preferred treatment modality in localized gastric GISTs $[1,3,9]$. Previously a $1-2 \mathrm{~cm}$ margin was accepted to be sufficient $[10,22]$, but it has recently been shown that resection of the tumor and a microscopic negative surgical border is also sufficient [2]. Addition of lymph dissection to surgical resection is unnecessary since GISTs do not metastasize by the lymphatic route [9]. For many researchers limited approaches like local excision or wedge resection are suitable for gastric GISTs, local excision or segmental resection is suitable for duodenal GISTs, segmental resection is suitable for small intestinal or colonic GISTs, and transanal excision is suitable for rectal GISTs [2,9]. Some cases may require wide resection because of tumor size and localization $[11,23]$. Tumor rupture and spread are related to worsening of the illness, tumor recurrences and short survival and these should be prevented during surgery [7]. Colorectal GISTs in distant locations are hard to manage and this is related to bad prognosis [11]. In our gastric GIST case, enucleation was tried first as it was located proximally. However, when no success was achieved, a limited resection (proximal gastrectomy) was done. In the duodenal case, a wide resection (Whipple operation) was performed because of pancreatic invasion. In the jejunal case, a segmental resection was performed as suggested in the literature. Lymph dissection was not performed. There were no postoperative complications.

Although the National Comprehensive Cancer Network recommends laparoscopic treatment of tumors $<2 \mathrm{~cm}$ as an optimal treatment of patients with gastric GISTs [23], larger tumors can also be excised safely $[10,24]$. In a study comparing laparoscopy and open surgery, laparoscopic group of patients were found to have less bleeding and shorter hospitalization periods [10]. Recent studies point out that minimally invasive surgery like endoscopy could be used in small gastric GISTs [25]. However, since these studies are unicentral with a small number of cases, the reliability and efficiency of this treatment is unclear. In general, if tumor size is $>3 \mathrm{~cm}$ and EUS reveals muscularis propria invasion, endoscopic enucleation should be avoided [26].

With a better understanding of prognostic factors in surgically resected primary GISTs, postoperative follow-up strategies and adjuvant treatments have evolved [27]. It has been proved that imatinib mesylate is very effective in metastatic GISTs, though its effectivity is dependent on the state of mutation [28]. It has been determined that in tumors with KIT exon 11 mutation, better results were achieved, while in tumors with exon 9 mutation and in tumors without KIT or PDGFRA mutation, the response rate was very low. Good results were obtained when sunitinib maleate (multikinase inhibitor) was given to patients with metastatic GISTs (with or without KIT exon 9 mutation) who had worsening of their illness despite imatinib treatment [27]. Most of the KIT mutations in GISTs involve exon 11, whereas other KIT mutations are exon 9, 13 and 17 in decreasing order. While GISTs with mutations on exon 11 are most sensitive to imatinib when compared to mutations on exon 9 and 13, mutation on exon 17 represents primary resistance to imatinib [29]. Although cases with mutations on exon 11 have low-risk 
disease usually with smaller tumors in addition to good prognosis and usually involve older patients especially in gastric locations, exon 9 mutations are associated with extragastric locations and bad prognosis with larger tumor size [30]. The most common locations for metastasis are the liver, peritoneum, bones and lungs [11].

In all GIST cases (benign or malignant), long-term follow-up is essential. There is no routine procedure for follow-up. Physical examination should be performed once every 3-4 months for the first two years, lung X-rays, abdominal CT and blood tests once every year, and after operation upper gastrointestinal endoscopy once every 6 months for 2 years and then once a year. Positron emission tomography, however, should be obtained if any anomalies are detected in MRI or CT [7]. Recurrences are most frequently seen during the first 2 years and thus follow-up should be done with great care during this period $[3,7]$. In another study, controls are recommended on a 3-6-month basis for the first 3 years, then on a yearly basis for the consecutive 10 years [11]. Our cases were followed by the oncology department, and only the patient with duodenal GIST was given imatinib treatment as he was in the high-risk group.

In conlusion, as diagnostic tools and methods have improved, with the help of immunohistochemical analyses, GISTs can be diagnosed more easily, thus major surgical resections can be prevented and patients can be cured with minimally invasive procedures.

Table 1. Patient demographics and complaints

\begin{tabular}{llllll}
\hline & Sex & Age & Location & Symptoms & Risk category \\
\hline Case 1 & male & 27 & duodenum & abdominal pain & high \\
Case 2 & male & 62 & stomach & abdominal pain & medium \\
Case 3 & male & 38 & jejunum & abdominal pain, rectal bleeding & low \\
\hline
\end{tabular}

Table 2. Pathologic and immunohistochemical data

\begin{tabular}{llllll}
\hline & $\begin{array}{l}\text { Tumor diameter } \\
(\mathrm{cm})\end{array}$ & $\begin{array}{l}\text { Number of } \\
\text { mitoses (50 HPF) }\end{array}$ & $\begin{array}{l}\text { C-kit (CD117) } \\
\text { positivity }\end{array}$ & $\begin{array}{l}\text { CD34 } \\
\text { positivity }\end{array}$ & $\begin{array}{l}\text { Necrosis/ } \\
\text { ulceration }\end{array}$ \\
\hline Case1 & 24 & 0 & +++ & +++ & $+/-$ \\
Case 2 & 10 & $<5$ & +++ & +++ & $-/+$ \\
Case 3 & 2.5 & $<1$ & +++ & +++ & $-/+$ \\
\hline
\end{tabular}

$\mathrm{HPF}=$ High power field. 
Table 3. Risk determination criteria in GISTs (US NIH 2001 consensus report)

\begin{tabular}{lll}
\hline & Tumor diameter $(\mathrm{cm})$ & Mitosis number $(50 \mathrm{HPF})$ \\
\hline Very low risk & $<2$ & $<5$ \\
Low risk & $\geq 2$ to $\leq 5$ & $<5$ \\
Medium risk & $<5$ & $6-10$ \\
High risk & $5-10$ & $<5$ \\
& $>5$ & $>5$ \\
& anyone $>10$ & anyone $>10$ \\
\hline
\end{tabular}

$\mathrm{HPF}=$ High power field

Fig. 1. Abdominal CT of case 1 following oral contrast ingestion. There is a huge mass with a necrotic central part at the right side of the abdomen.

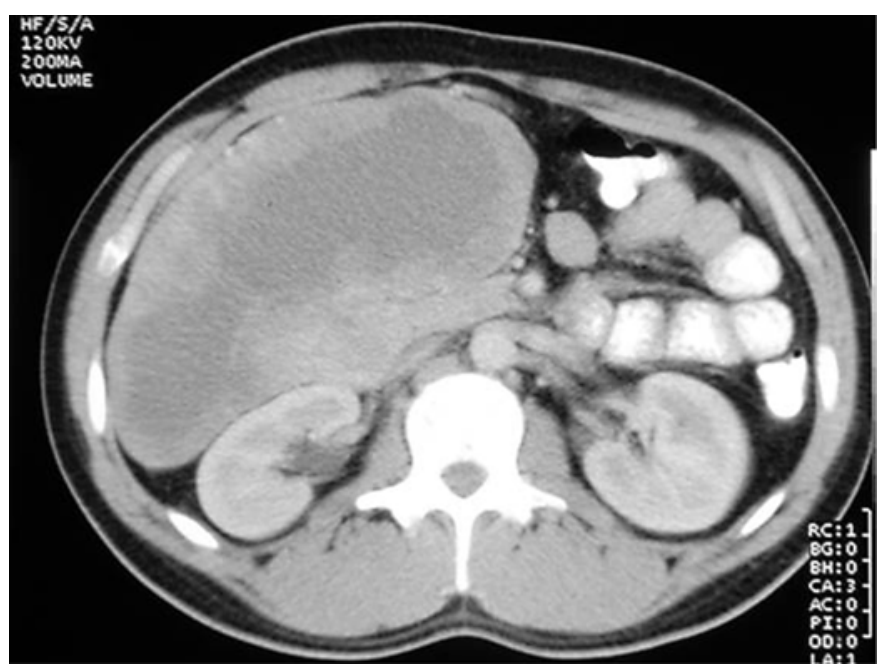




\begin{tabular}{r|l|l|l} 
Case Reports in & $\begin{array}{l}\text { Case Rep Gastroenterol 2010;4:250-260 } \\
\text { D0I: 10.1159/000319167 }\end{array}$ & Published online: July 26, 2010 & $\begin{array}{l}\text { O 2010 S. Karger AG, Basel } \\
\text { ISSN 1662-0631 } \\
\text { www.karger.com/crg }\end{array}$ \\
\hline
\end{tabular}

Fig. 2. Fat suppression. T1 axial MR image of case 1 shows a mass with a hyperintense center (mucinous? bleeding?). The border between the pancreas and the mass is unclear and it was interpreted as invasion.

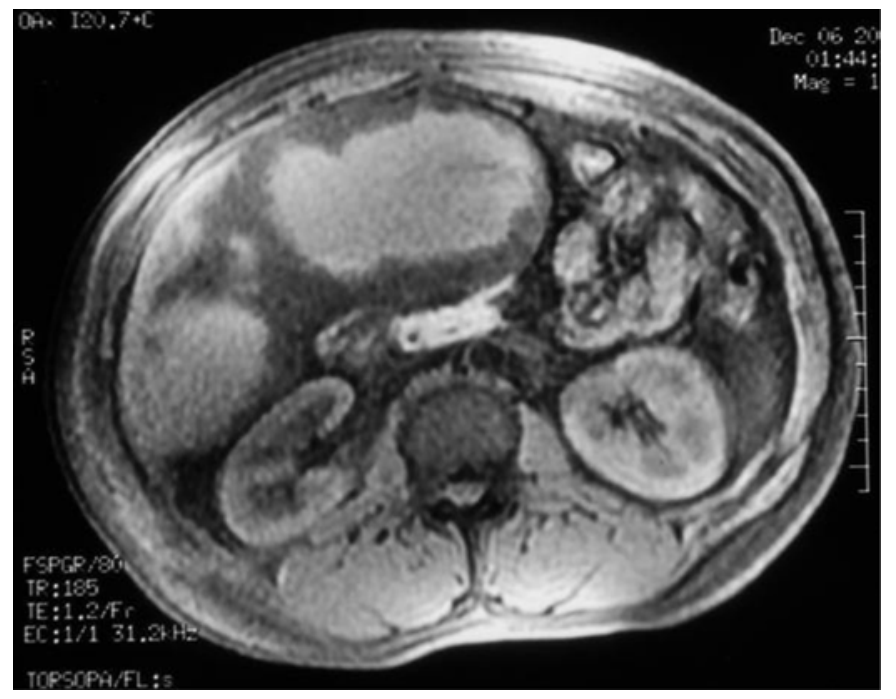

Fig. 3. Fat suppression. T1 axial MR slice of case 2 with contrast enhancement. There is a soft tissue mass (arrows) protruding to the fundus of the stomach, with heterogenic contrast.

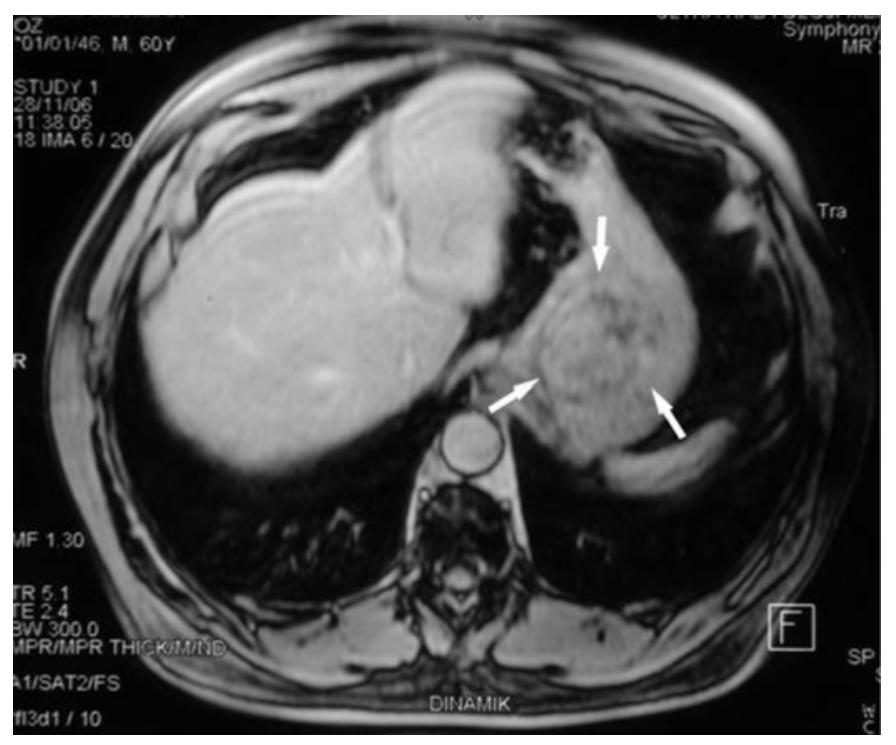




\begin{tabular}{r|l|l|l} 
Case Reports in & $\begin{array}{l}\text { Case Rep Gastroenterol 2010;4:250-260 } \\
\text { D0I: 10.1159/000319167 }\end{array}$ & Published online: July 26, 2010 & $\begin{array}{l}\text { O 2010 S. Karger AG, Basel } \\
\text { ISSN 1662-0631 } \\
\text { www.karger.com/crg }\end{array}$ \\
\hline
\end{tabular}

Fig. 4. Increased activity in the upper left quadrant of case 3 at the 2 nd hour. The activity has moved towards the inferior quadrant at the 4 th hour.

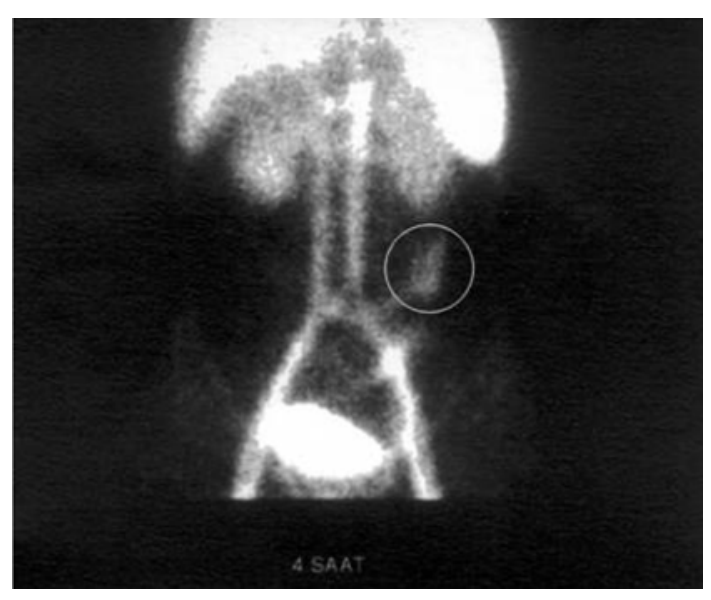

Fig. 5. Polypoid mass in the proximal jejunum in case 3 (capsule endoscopy image).

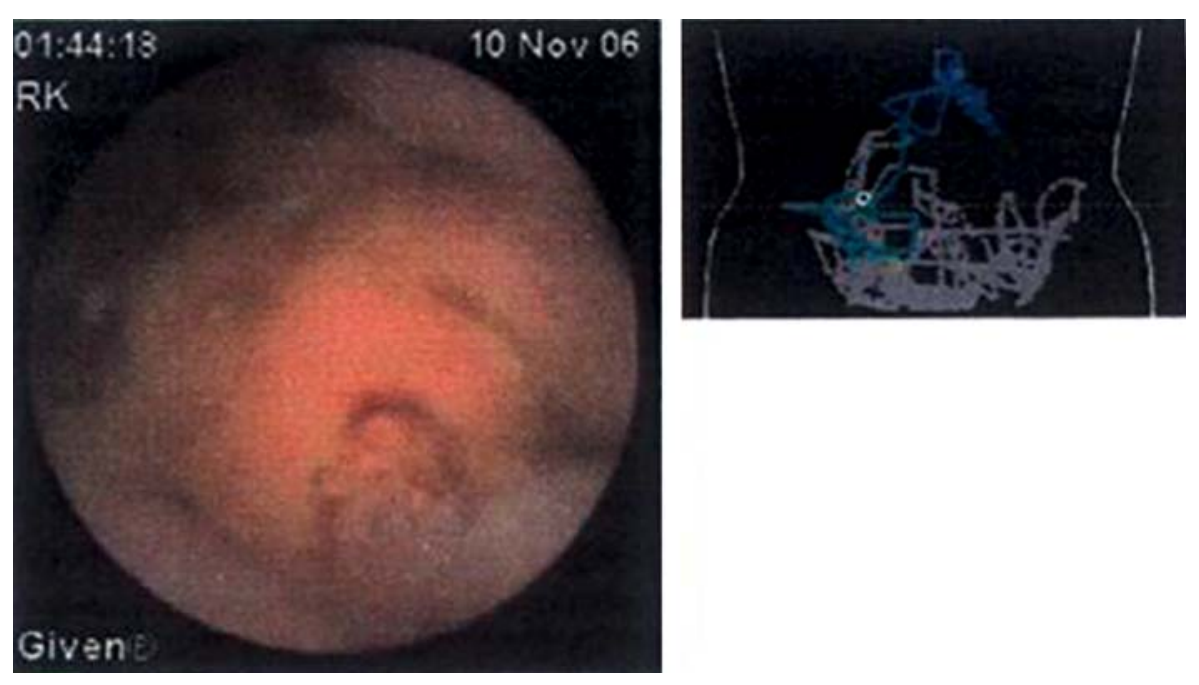




\begin{tabular}{r|l|l|l} 
Case Reports in & $\begin{array}{l}\text { Case Rep Gastroenterol 2010;4:250-260 } \\
\text { D01: 10.1159/000319167 }\end{array}$ & Published online: July 26, 2010 & $\begin{array}{l}\odot \text { 2010 S. Karger AG, Basel } \\
\text { ISSN 1662-0631 } \\
\text { www.karger.com/crg }\end{array}$ \\
\hline
\end{tabular}

Fig. 6. Polypoid mass in the jejunum seen during double balloon enterescopy in case 3 .

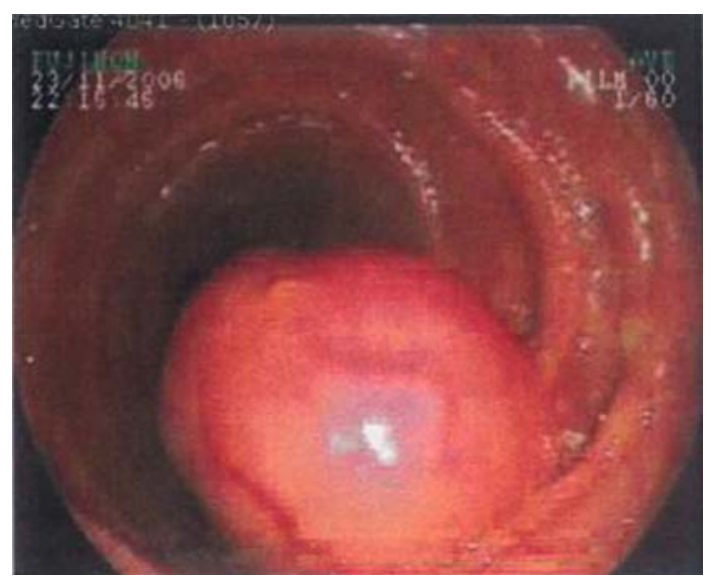

Fig. 7. C-kit was strongly positive in all patients. Hematoxylin and eosin, $40 \times 10$.

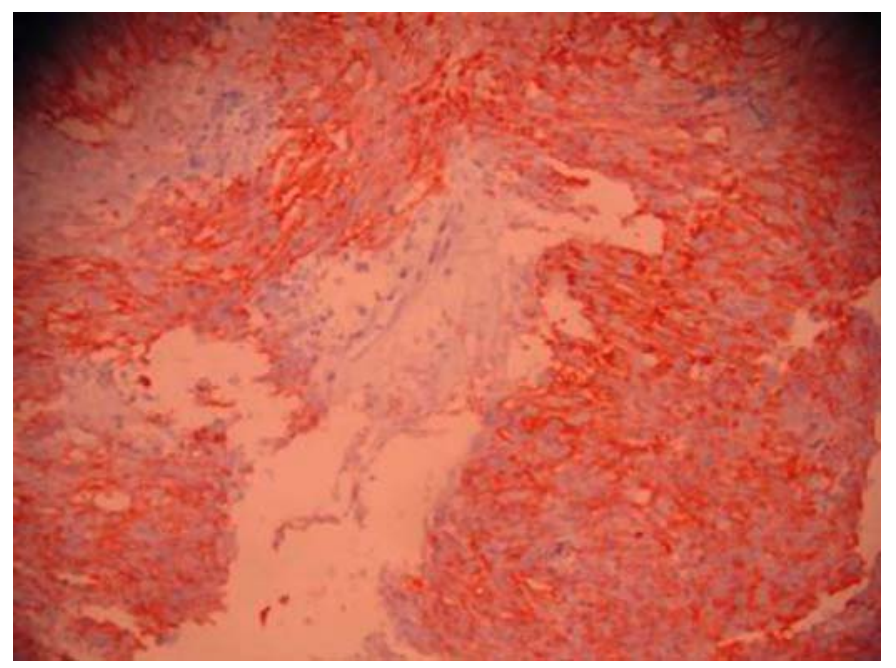




\section{References}

1 Corless CL, Fletcher JA, Heinrich MC: Biology of gastrointestinal stromal tumors. J Clin Oncol 2004;22:3813-3825.

2 DeMatteo RP, Lewis JJ, Leung D, et al: Two hundred gastrointestinal stromal tumors: recurrence patterns and prognostic factors for survival. Ann Surg 2000;231:51-58.

-3 Nowain A, Bhakta H, Pais S, et al: Gastrointestinal stromal tumors: clinical profile, pathogenesis, treatment strategies and prognosis. J Gastroenterol Hepatol 2005;20:818-824.

4 Graadt van Roggen JF, van Velthuysen ML, Hogendoorn PC: The histopathological differential diagnosis of gastrointestinal stromal tumours. J Clin Pathol 2001;54:96-102.

5 Fletcher CD, Berman JJ, Corless C, et al: Diagnosis of gastrointestinal stromal tumors: a consensus approach. Hum Pathol 2002;33:459-465.

-6 Miettinen M, Virolainen M, Sarlomo-Rikala M: Gastrointestinal stromal tumors: value of CD34 antigen in their identification and separation from true leiomyomas and schwannomas. Am J Surg Pathol 1995;19:207-216.

7 Novitsky YW, Kercher KW, Sing RF, et al: Long-term outcomes of laparoscopic resection of gastric gastrointestinal stromal tumors. Ann Surg 2006;243:738-744.

8 Miettinen M, Sobin LH, Lasota J: Gastrointestinal stromal tumors of the stomach: a clinicopathologic, immunohistochemical, and molecular genetic study of 1,765 cases with long-term follow-up. Am J Surg Pathol 2005;29:52-68.

-9 Hassan I, You YN, Shyyan R, et al: Surgically managed stromal tumors. Ann Surg Oncol 2007;15:52-59.

10 Matthews BD, Walsh RM, Kercher KW, et al: Laparoscopic vs open resection of gastric stromal tumors. Surg Endosc 2002;16:803-807.

- 11 Hassan I, You YN, Dozois EJ, et al: Clinical, pathologic and immunhistochemical characteristics of gastrointestinal stromal tumors of the colon and rectum: implications for surgical management and adjuvant therapies. Dis Colon Rectum 2006;49:609-615.

12 Blanke CD, Corless CL: State-of-the-art therapy for gastrointestinal stromal tumors. Cancer Invest 2005;23:274-280.

13 Bümming P, Ahlman H, Andersson J, et al: Population-based study of the diagnosis and treatment of gastrointestinal stromal tumours. Br J Surg 2006;93:836-843.

14 Kim HC, Lee JM, Kim KW, et al: Gastrointestinal stromal tumors of the stomach: CT findings and prediction of malignancy. AJR Am J Roentgenol 2004;183:893898.

15 Miettinen M, El-Rifai W, Sobin LH, et al: Evaluation of malignancy and prognosis of gastrointestinal stromal tumors: a review. Hum Pathol 2002;33:478-483.

16 Emory TS, Sobin LH, Lukes L, et al: Prognosis of gastrointestinal smooth-muscle (stromal) tumors: dependence on anatomic site. Am J Surg Pathol 1999;23:82-87.

17 Nickl NJ: Gastrointestinal stromal tumors: new progress, new questions. Curr Opin Gastroenterol 2004;20:482-487.

18 Chak A, Canto MI, Rosch T, et al: Endosonographic differentiation of benign and malignant stromal cell tumors. Gastrointest Endosc 1997;45:468-473.

19 Nilsson B, Bumming P, Meis-Kindblom JM, et al: Gastrointestinal stromal tumors: the incidence, prevalence, clinical course, and prognostication in the preimatinib mesylate era - a population-based study in western Sweden. Cancer 2005;103:821-829.

20 Miettinen M, Sobin LH, Sarlomo-Rikala M: Immunohistochemical spectrum of GISTs at different sites and their differential diagnosis with a reference to CD117 (KIT). Mod Pathol 2000;13:1134-1142.

-21 Antonescu CR, Viale A, Sarran L, et al: Gene expression in gastrointestinal stromal tumors is distinguished by KIT genotype and anatomic site. Clin Cancer Res 2004;10:3282-3290.

22 Cuschieri A: Laparoscopic gastric resection. Surg Clin North Am 2000;80:12691284 . 
23 Demetri GD, Blanke CD: NCCN Task Force Report. Optimal management of patients with gastrointestinal stromal tumors (GIST): expansion and update of NCCN Clinical Guidelines. J Natl Comp Cancer Network 2004;2(suppl):1-26.

24 Nguyen NT, Jim J, Nguyen A, et al: Laparoscopic resection of gastric stromal tumor: a tailored approach. Am Surg 2003;69:946-950.

25 Choi SM, Kim MC, Jung GJ, et al: Laparoscopic wedge resection for gastric GIST: long-term follow-up results. Eur J Surg Oncol 2007;33:444-447.

26 Katoh T, Itoh Y, Mohri T, et al: Endoscopic enucleation of gastrointestinal stromal tumors of the stomach: Report of five cases. World J Gastroenterol 2008;14:2609-2611.

27 DeMatteo RP, Gold JS, Saran L, et al: Tumor mitotic rate, size and location independently predict recurrence after resection of primary gastrointestinal stromal tumor (GIST). Cancer 2008;112:608-614.

28 Demetri GD, von Mehren M, Blanke CD, et al: Efficacy and safety of imatinib mesylate in advanced gastrointestinal stromal tumors. N Engl J Med 2002;347:472-480.

29 Lasota J, Corless CL, Heinrich MC, et al: Clinicopathologic profile of gastrointestinal stromal tumors (GISTs) with primary KIT exon 13 or exon 17 mutations: a multicenter study on 54 cases. Mod Pathol 2008;21:476-484.

30 Longley BJ, Reguera MJ, Ma Y: Classes of c-KIT activating mutations: proposed mechanisms of action and implications for disease classification and therapy. Leuk Res 2001;25:571-576. 